\title{
The Swedish Twin Registry in the Third Millennium: An Update
}

\author{
Paul Lichtenstein,' Patrick F. Sullivan,',2 Sven Cnattingius,' Margaret Gatz,,', Sofie Johansson,' Eva Carlström,' \\ Camilla Björk,' Magnus Svartengren, ${ }^{4}$ Alicja Wolk, ${ }^{5}$ Lars Klareskog, ${ }^{6}$ Ulf de Faire, ${ }^{7}$ Martin Schalling, ${ }^{8}$ \\ Juni Palmgren,' and Nancy L. Pedersen ${ }^{1,3}$ \\ ' Department of Medical Epidemiology and Biostatistics, Karolinska Institutet, Stockholm, Sweden \\ ${ }^{2}$ Department of Genetics, University of North Carolina, Chapel Hill, North Carolina, United States of America \\ ${ }^{3}$ Department of Psychology, University of Southern California, Los Angeles, California, United States of America \\ ${ }^{4}$ Department of Public Health Sciences, Division of Occupational Medicine, Karolinska Institutet and Stockholm County Council, Department of \\ Occupational and Environmental Health, Stockholm Sweden \\ ${ }^{5}$ Institute of Environmental Medicine, Division of Nutritional Epidemiology, Karolinska Institutet, Stockholm, Sweden \\ ${ }^{6}$ Department of Medicine, Karolinska University Hospital, Karolinska Institutet, Stockholm, Sweden \\ ${ }^{7}$ Institute of Environmental Medicine, Division of Cardiovascular Epidemiology, Karolinska Institutet, Stockholm, Sweden \\ ${ }^{8}$ Department of Molecular Medicine and Surgery, Karolinska Institutet, Stockholm, Sweden
}

\begin{abstract}
The Swedish Twin Registry was first established in the late 1950s. Today it includes more than 170,000 twins - in principle all twins born in Sweden since 1886. In this article we describe some ongoing and recently completed projects based on the registry. In particular, we describe recent efforts to screen all twins born between 1959 and 1985, and young twin pairs when they turn 9 and 12 years of age. For these studies, we present initial frequencies of common conditions and exposures.
\end{abstract}

The Swedish Twin Registry (STR) is a unique resource for the scientific community. It was first established in the late 1950 s to study the importance of smoking and alcohol consumption on cancer and cardiovascular diseases while controlling for genetic propensity to disease. Today the STR includes 170,176 twins in 85,088 pairs (Table 1 ), in principle all twins born in Sweden between 1886 and 2000. Of these, 137,414 twins are still alive and living in Sweden. The number of twin pairs where both twins are alive and living in Sweden is 61,508 (Table 1). Previous data collection by the STR comprised several questionnaires during the 1960 s and 1970 s, and the SALT telephone interviews conducted from 1998 to 2002. These have been described in detail previously (Lichtenstein et al., 2002; Pedersen et al., 2002). The STR database is regularly updated with current addresses, as well as information about cancer diagnoses, hospital discharges and inpatient diagnoses, cause of death, conditions during birth, and vital status (all this information is passed on from the relevant national health care registries). Zygosity is assigned based on questions about intrapair similarities in childhood. This method has been validated repeatedly with DNA as having $98 \%$ or higher accuracy (Lichtenstein et al., 2002) .

In 2002 we described the history and structure of the STR, including a summary of much of the STR research prior to 2002 (Lichtenstein et al., 2002; Pedersen et al., 2002). Several recently completed and ongoing projects have also been described in other publications (Cameron et al., 2002; Evengard et al., 2005; Finkel \& Pedersen, 2004; Gatz et al., 2005; Kato et al., 2006a; Lichtenstein et al., in press; Michaelsson et al., 2005; Wirdefeldt et al., 2004). Here, we describe the progress and updates of the registry since 2002, focusing on older twins born before 1958 (Screening Across the Lifespan Twin Study: SALT), young adult to middle-aged twins born 1959 to 1985 (Study of Twin Adults: Genes and Environment: STAGE), twin children born since 1992 (Child and Adolescent Twin Study in Sweden: CATSS), and a study in which birth information has been collected for all twins born 1926 to 1958 .

\section{The SALT Study: Screening of Diseases in Older Twins}

The SALT study was initiated in 1998, with the purpose of screening all twins born before 1958 for most common complex diseases, regardless of the status of their twin partner. The computer assisted telephone interview focused first on twins over 65 years of age at interview, and then proceeded to younger twins, and was completed in 2002. Since our last report about SALT (Lichtenstein et al., 2002),

Received 31 July, 2006; accepted 19 September, 2006.

Address for Correspondence: Paul Lichtenstein, Department of Medical Epidemiology and Biostatistics, Box 281, SE-171 77

Stockholm, Sweden.E-mail: paul.lichtenstein@ki.se 
Table 1

Number of Pairs in the Swedish Twin Registry

\begin{tabular}{|c|c|c|c|c|c|c|}
\hline \multirow[t]{3}{*}{ Birth cohort } & \multicolumn{3}{|c|}{ Number of twin pairs in the Swedish Twin Registry } & \multicolumn{3}{|c|}{ Number of twin pairs still alive and living in Sweden } \\
\hline & \multicolumn{2}{|c|}{ Same-sexed pairs } & \multirow{2}{*}{$\begin{array}{l}\text { Opposite- } \\
\text { sexed pairs }\end{array}$} & \multicolumn{2}{|c|}{ Same-sexed pairs } & \multirow{2}{*}{$\begin{array}{l}\text { Opposite- } \\
\text { sexed pairs }\end{array}$} \\
\hline & Male & Female & & Male & Female & \\
\hline $1886-1925$ & 4813 & 1654 & 6059 & 655 & 1441 & 688 \\
\hline 1926-1958 & 8855 & 10,474 & 9097 & 7189 & 7907 & 5735 \\
\hline 1959-1986 & 8845 & 8688 & 7653 & 6889 & 6874 & 6133 \\
\hline 1987-1992 & 2749 & 2608 & 2326 & 2081 & 2207 & 1758 \\
\hline 1992-2000² & 3768 & 3948 & 3551 & 4025 & 3757 & 4169 \\
\hline Total & 29,030 & 27,372 & 28,686 & 20,839 & 22,186 & 18,483 \\
\hline
\end{tabular}

Note: 'Until June 1992.

${ }^{2}$ From July 1992.

which described the design, procedure, and prevalence rates for respondents over the age of 55, we have now completed data collection for the entire cohort of twins born 1886 to 1958 . The number of individual twins and complete twin pairs that have responded in the SALT study are presented in Table 2. Response rates for those eligible (still alive and living in Sweden) were $65 \%$ for the cohort born 1886 to 1925 , and $74 \%$ for the cohort born 1926 to 1958 . Notably, data are available in the SALT for both same-sex and opposite-sex twins. For same sex-twins, data from the STR are also available from the 1960s and 1970s. Thus, many analyses use information from both the STR and SALT to understand lifespan origins of chronic diseases later in life.

Since the completion of SALT, four studies with additional data collection from twins with a specific disease or syndrome have been initiated, and in some cases, completed (the HARMONY study of dementia, Gatz et al., 2005; Parkinson's disease in Swedish twins,
Wirdefeldt et al., 2004; chronic fatigue syndrome, Evengard et al., 2005; and chronic obstructive pulmonary disease). In addition, a number of analyses of the SALT cohort have been published (e.g., Bulik et al., 2006; Cameron et al., 2002; Crowe, et al., in press; Gatz et al., 2006; Kato et al., 2006a, 2006b; Kendler, et al., 2006; Mackintosh, et al., 2006; Michaelsson et al., 2005; Mucci, et al., 2005; Rasgon et al., 2005; Soldani, et al., 2005; Svensson, et al., 2004; Wirdefeldt, et al., 2004). As these studies have been described elsewhere, we focus here on a new initiative involving the SALT cohort, establishing a biobank.

\section{Biobanking SALT}

One of the key goals of the STR is to obtain DNA from as many twins as possible and to establish a biobank. Toward that end, we are obtaining whole blood samples for DNA extraction and serum for clinical chemistries from at least 10,000 pairs of twins who have participated in SALT. As of August 2006, we have collected serum and DNA from 5350 individ-

\section{Table 2}

Number of Individuals and Pairs in Recent Data-Collection Efforts

\begin{tabular}{|c|c|c|c|c|c|c|c|c|c|c|}
\hline \multirow[t]{3}{*}{ Birth cohort } & \multirow[t]{3}{*}{$\begin{array}{c}\text { Data } \\
\text { collection }\end{array}$} & \multicolumn{2}{|c|}{$\begin{array}{l}\text { Number of individuals who } \\
\text { responded to the latest } \\
\text { data collection }\end{array}$} & \multicolumn{7}{|c|}{ Number of complete twin pairs who responded to the latest data collection } \\
\hline & & \multirow[t]{2}{*}{ Male } & \multirow[t]{2}{*}{ Female } & \multicolumn{3}{|c|}{ Male } & \multicolumn{3}{|c|}{ Female } & \multirow[b]{2}{*}{$\begin{array}{c}\text { Unlike } \\
\text { sexed pairs }\end{array}$} \\
\hline & & & & Monozygotic & Dizygotic & $\begin{array}{l}\text { Unknown } \\
\text { zygosity }\end{array}$ & Monozygotic & Dizygotic & $\begin{array}{l}\text { Unknown } \\
\text { zygosity }\end{array}$ & \\
\hline 1886-1925 & SALT & 2544 & 3655 & 177 & 305 & 3 & 344 & 577 & 8 & 443 \\
\hline 1926-1958 & SALT & 18,335 & 20,385 & 1970 & 3061 & 205 & 2385 & 3450 & 154 & 4238 \\
\hline $1959-1986^{1}$ & STAGE & 11,251 & 14,113 & 838 & 527 & 81 & 1483 & 952 & 83 & 2582 \\
\hline \multicolumn{11}{|l|}{$1987-1992^{2}$} \\
\hline $1992-2000^{3}$ & CATSS & $4074^{4}$ & $3860^{4}$ & $581^{4}$ & $616^{4}$ & $181^{4}$ & $585^{4}$ & $501^{4}$ & $185^{4}$ & $1318^{4}$ \\
\hline
\end{tabular}


uals, of whom 2150 are twin pairs. Through collaboration with GenomEUtwin (Peltonen, 2003), genome scans (1000 marker set) have been completed on 510 same-sex dizygotic (DZ) pairs and through EuroClot, 391 individuals have provided plasma for evaluation of clotting factors. Our strategy has been to start with the oldest intact pairs and collect samples from pairs in successively younger ages.

\section{The Study of Twin Adults: Genes and \\ Environment (STAGE) - Exposures and Illnesses in Middle Age Twins}

For the first time, we contacted cohorts of twins in the STR born after 1958. STAGE is, at this time, the world's largest web-based survey, including 43,000 monozygotic (MZ), same- and opposite-sex DZ twins born in Sweden 1959-1985. Much like SALT, the purpose was to screen for most common complex diseases, although a great deal of attention was put into evaluating exposure relevant during young adulthood and midlife (Table 3). Because this cohort of twins is the same age the middle cohort of the STR was when contacted in 1972 (i.e., those born 1926-1958), we have a unique opportunity to test for cohort differences in both exposure to, and prevalence of, diseases.

\section{Procedures}

All twins born from 1959 to 1985 were contacted with an invitation letter containing information about

Table 3

Sections included in the Study of Twin Adults: Genes and Environment (STAGE)

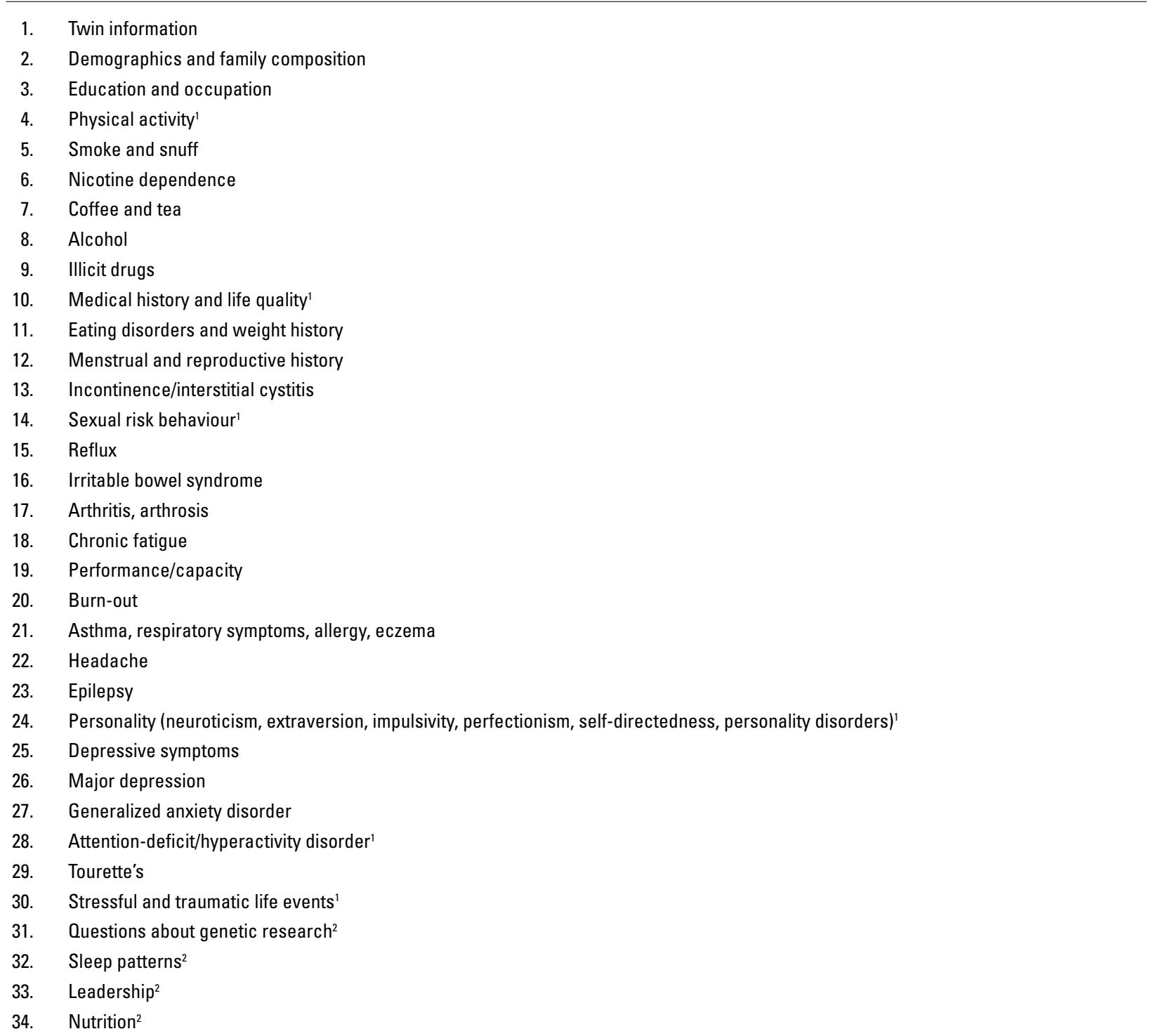

Note: 'Section included in paper questionnaire mailed to the 7030 twins who responded to the telephone interview.

'These sections were presented as 'voluntary sections' at the end of the questionnaire. Thus, the twins were informed that the formal questionnaire was completed, but that the extra sections could be completed if they wanted to. Fifty-eight per cent of those who responded to the web questionnaire also responded to these 'extra' questions. 
Table 4

Lifetime Prevalence of Common Conditions Based on Self-Reports During STAGE

\begin{tabular}{|c|c|c|c|c|}
\hline & Women & Men & Total & Карра* \\
\hline High blood pressure & $8.8 \%$ & $6.0 \%$ & $7.7 \%$ & 0.69 \\
\hline Lipid disorders & $2.2 \%$ & $4.3 \%$ & $3.1 \%$ & - \\
\hline Angina pectoris & $0.4 \%$ & $0.7 \%$ & $0.5 \%$ & - \\
\hline Myocardial infarction & $0.1 \%$ & $0.2 \%$ & $0.1 \%$ & - \\
\hline Claudication & $0.2 \%$ & $0.3 \%$ & $0.3 \%$ & - \\
\hline Venous thrombosis & $2.0 \%$ & $0.5 \%$ & $1.4 \%$ & - \\
\hline Narrowing of neck arteries & $0.3 \%$ & $0.4 \%$ & $0.3 \%$ & - \\
\hline Irregular cardiac rhythms/atrial fibrillation & $3.5 \%$ & $4.1 \%$ & $3.8 \%$ & - \\
\hline Chronic bronchitis & $5.7 \%$ & $2.8 \%$ & $4.2 \%$ & 0.26 \\
\hline Rheumatoid arthritis & $1.2 \%$ & $0.6 \%$ & $0.9 \%$ & - \\
\hline Knee joint problem & $12.7 \%$ & $14.3 \%$ & $13.4 \%$ & 0.53 \\
\hline Sciatica & $14.8 \%$ & $8.2 \%$ & $12.2 \%$ & 0.47 \\
\hline Hip joint problem & $5.6 \%$ & $2.6 \%$ & $4.4 \%$ & 0.56 \\
\hline Disabled & $3.4 \%$ & $3.0 \%$ & $3.2 \%$ & - \\
\hline Bechterew's disease & $0.4 \%$ & $0.6 \%$ & $0.5 \%$ & - \\
\hline Back pain & $35.7 \%$ & $33.9 \%$ & $34.9 \%$ & 0.58 \\
\hline Neck pain & $21.2 \%$ & $13.8 \%$ & $18.2 \%$ & 0.29 \\
\hline Shoulder pain & $15.3 \%$ & $12.7 \%$ & $14.0 \%$ & 0.49 \\
\hline Scoliosis & $6.0 \%$ & $2.1 \%$ & $4.4 \%$ & 0.69 \\
\hline Stomach or intestinal problems & $25.4 \%$ & $17.3 \%$ & $22.1 \%$ & 0.46 \\
\hline Crohn's disease & $0.4 \%$ & $0.4 \%$ & $0.4 \%$ & - \\
\hline Ulcerative colitis & $0.8 \%$ & $0.6 \%$ & $0.7 \%$ & - \\
\hline Recurring urinary tract problems & $12.2 \%$ & $1.1 \%$ & $7.7 \%$ & 0.60 \\
\hline Prostate problem & & $1.9 \%$ & $1.9 \%$ & - \\
\hline Multiple sclerosis & $0.2 \%$ & $0.1 \%$ & $0.2 \%$ & - \\
\hline Psoriasis & $3.4 \%$ & $3.0 \%$ & $3.2 \%$ & 0.71 \\
\hline Diabetes & $1.2 \%$ & $1.0 \%$ & $1.1 \%$ & - \\
\hline Goiter & $2.5 \%$ & $0.2 \%$ & $1.6 \%$ & - \\
\hline Other glandular disease & $1.5 \%$ & $0.7 \%$ & $1.2 \%$ & - \\
\hline Gall bladder problem & $5.1 \%$ & $1.3 \%$ & $3.5 \%$ & 0.58 \\
\hline Liver disease & $0.2 \%$ & $0.4 \%$ & $0.3 \%$ & - \\
\hline Gout & $0.2 \%$ & $0.5 \%$ & $0.4 \%$ & - \\
\hline Kidney disease & $1.7 \%$ & $1.3 \%$ & $1.5 \%$ & - \\
\hline Glandular fever/infectious mononucleosis & $9.1 \%$ & $7.1 \%$ & $8.3 \%$ & 0.75 \\
\hline Migraine & $28.9 \%$ & $14.6 \%$ & $23.1 \%$ & 0.77 \\
\hline Dizziness & $27.7 \%$ & $12.7 \%$ & $21.6 \%$ & 0.51 \\
\hline Cancer & $1.8 \%$ & $1.1 \%$ & $1.5 \%$ & - \\
\hline Depression & $25.9 \%$ & $16.6 \%$ & $22.1 \%$ & 0.60 \\
\hline Bipolar disorder & $0.6 \%$ & $0.1 \%$ & $0.5 \%$ & - \\
\hline Anxiety attacks & $15.5 \%$ & $9.1 \%$ & $12.9 \%$ & 0.83 \\
\hline Specific phobia & $12.0 \%$ & $5.9 \%$ & $9.5 \%$ & 0.53 \\
\hline Problems with drugs or alcohol & $2.0 \%$ & $3.2 \%$ & $2.5 \%$ & 0.66 \\
\hline Eating Disorder & $9.3 \%$ & $0.8 \%$ & $5.9 \%$ & 0.76 \\
\hline Obsessive compulsive disorder & $4.2 \%$ & $2.8 \%$ & $3.7 \%$ & 1.00 \\
\hline $\begin{array}{l}\text { Attention-deficit/hyperactivity disorder/deficits in attention, } \\
\text { motor control and perception/minimal brain dysfunction }\end{array}$ & $0.2 \%$ & $0.2 \%$ & $0.2 \%$ & - \\
\hline Tourette's disease & $0.2 \%$ & $0.3 \%$ & $0.3 \%$ & - \\
\hline Schizophrenia & $0.1 \%$ & $0.2 \%$ & $0.1 \%$ & - \\
\hline Autism spectrum disease & $0.1 \%$ & $0.2 \%$ & $0.1 \%$ & - \\
\hline Cramp attacks & $2.6 \%$ & $2.7 \%$ & $2.6 \%$ & 0.26 \\
\hline Minor epileptic seizures & $1.8 \%$ & $1.6 \%$ & $1.7 \%$ & 0.74 \\
\hline Herpes & $29.2 \%$ & $25.4 \%$ & $27.7 \%$ & 0.84 \\
\hline Lip fissure, jaw fissure or cleft palate & $0.3 \%$ & $0.4 \%$ & $0.3 \%$ & - \\
\hline
\end{tabular}

Note: ${ }^{*}$ Calculations based on responses from 100 individuals who completed both the web questionnaire and telephone interview (for the purpose of retest). 
the project. They were provided with the website address of the project's homepage and given a personal login. The letter also contained a response form where respondents could indicate if they preferred a telephone interview. For logistic purposes, the mailing was done in four batches between May 20, 2005 and June 1, 2005. Three reminders were sent out to twins who did not respond to the webbased survey. The first reminder was sent 2 weeks after the information letter, the second 2 weeks after the first reminder, and the last after summer had ended (September 2005). Two reminders were also sent to twins who began, but failed to complete, the web questionnaire. In addition, an electronic reminder was sent to twins who had given us their email addresses. In the final reminder, twins were phoned and asked to complete the questionnaire.

After the three reminders, respondents who still had not responded were phoned and offered the opportunity to participate in a telephone interview instead. These interviews started in November 2005 and were completed in March 2006. For individuals who chose to participate in a telephone interview (performed by trained interviewers, using a computer-based data collection system), a supplementary paper questionnaire was mailed (see Table 3 for sections completed over the phone and those done via paper questionnaire).

One hundred twins were recontacted after 2 to 5 months in order to assess test-retest reliability, as well as to compare methods of data collection (i.e., web versus telephone interview).

\section{Participation Rates}

The sex distribution of the 42,582 eligible twins (i.e., pairs where both twins survived their first birthday) in the target population is approximately equal. The total response rate was $59.6 \%(N=25,364$; Table 2$)$. The response rate for the web questionnaire was $43.1 \%$ (49.9\% for women, $36.2 \%$ for men), and an additional $16.5 \%$ ( $16.0 \%$ women, $17.0 \%$ men) completed a telephone interview.

\section{Questionnaires and telephone interview}

The entire questionnaire contained approximately 1300 questions, in 34 sections (Table 3). Many sections in the questionnaire are presented in a 'branching' format, meaning that the individuals are asked follow-up questions if they respond positively to key introductory items. On average, respondents answered around 800 to 900 questions. The average time to complete either the web questionnaire or the telephone interview was 80 to 85 minutes. Respondents had the opportunity to take a break while responding - if they were participating via the web interview, when they logged on again they automatically began where they left off.

Table 4 describes the prevalence rates (by gender) from the STAGE study for some major health problems. Prevalent conditions were back and neck pain, stomach and intestinal problems, migraine, dizziness, depression, and herpes. The last column of Table 4 shows the agreement between web questionnaires and telephone interviews for the 100 individuals who were retested. The kappa-values were moderate, good, or excellent for most of the conditions, indicating that it will be possible to combine questionnaire and interview data for many analyses.

\section{Biobanking STAGE}

During 2005 we also performed a pilot study of DNA collection for determining zygosity from 200 twin pairs in the STAGE study. This feasibility study was successful; after one email reminder, $75.3 \%(N=301)$ donated DNA via finger-prick drops of blood on filter paper cards sent through ordinary mail. An additional five individuals preferred to donate DNA via saliva. We are currently evaluating the quality and quantity of the samples donated. If they are sufficient, the STR will probably soon approach all STAGE participants for DNA collection.

\section{STAGE follow-up}

Funding for STAGE follow-up has been obtained through grants from the National Cancer Institute (Genetic and environment determinants of smoking cessation, Patrick Sullivan, principal investigator) and from the National Institute of Digestive Disorders and Kidney Diseases (Interstitial Cystitis in Swedish Twins, Nancy Pedersen, principal investigator). Because the main goal of the smoking cessation project is the follow-up of individuals who are smokers or former smokers, all ever-tobacco users in this cohort will be recontacted three times at yearly intervals. The first recontact was launched during the summer of 2006.

\section{The Child and Adolescent Twin Study in Sweden (CATSS)}

The Child and Adolescent Twin Study in Sweden (CATTS), which aims to contact all twins in Sweden born since 1992, commenced in July 2004. In this study, a telephone interview is conducted with parents of all twins, not more than one month before or after their 9 th and 12 th birthdays. Approximately 1400 twin pairs are born in Sweden each year. All screening data are collected over the telephone by trained interviewers using a computerbased data collection system. In this screening phase we collect as much information as necessary to screen for most somatic and mental conditions. Special emphasis is put on symptoms that can determine whether a twin is likely to have a disease or a syndrome.

\section{Pilot Study and Participation Rates}

A pilot study testing the feasibility of the CATSS was performed on all 464 twin pairs born in July and August 1992 and 1995 (i.e., twins turning 9 or 12 during the summer of 2004). We were able to contact 
Table 5

Sections Included in the CATSS

\begin{aligned} & \hline 1. Demographics \\ & 2. Birth information \\ & 3. Zygosity \\ & 4. Weight and Length \\ & 5. Physical health \\ & 6. Prescribed medications \\ & 7. Symptoms of somatic problems \\ & 8. Psychiatric symptoms \\ & 9. Problematic personality traits \\ & 10. Environments \\ & \hline\end{aligned}

$98 \%$ of the families $(N=457)$, either by phone or by a home visit. Of the 457 twin families with contact information, $80.5 \%(N=368)$ completed the telephone interview. The pilot study was completed successfully, and the full-scale CATSS has been ongoing since September 2004. Interviews with parents of twins have now been completed for twins born from July 1992 to December 1993 (12 years old), and for twins born July
1995 to December 1996 (9 years old). Response rates continue to be high (81.2\%), and, as of June 2006, responses have been received from parents of 3967 twin pairs (Table 2).

\section{Telephone interview}

The entire interview contains 484 questions in 10 sections (Table 5). One section asks for demographic information about the parents. Birth information requested about the twins includes birth order and birthweight. Further, information about twins regarding current and past illnesses, prescribed medications, symptoms of somatic and psychiatric problems, problematic personality traits, and environments (physical activity, parenting, life events) is collected. The average time to complete the telephone interview is 64 minutes.

Table 6 describes the prevalence of some of the major health problems, and exposure by gender, found in the CATSS study. Common problems were different types of allergies and headache. Three per cent of parents reported a psychiatric diagnosis in their children; Twenty-five per cent of the children

\section{Table 6}

Lifetime Prevalence Rate (\%) of Major Conditions and Exposures Based on Parent Reports During CATSS (as of June 1, 2006)

\begin{tabular}{|c|c|c|c|}
\hline & $\begin{array}{c}\text { Girls } \\
N=3860 \\
\%\end{array}$ & $\begin{array}{c}\text { Boys } \\
N=4074 \\
\%\end{array}$ & $\begin{array}{c}\text { Total } \\
N=7934 \\
\%\end{array}$ \\
\hline \multicolumn{4}{|l|}{ Allergy } \\
\hline Asthma & 10.0 & 16.3 & 13.2 \\
\hline Hay fever & 11.3 & 16.8 & 14.1 \\
\hline Atopic eczema & 15.6 & 13.2 & 14.3 \\
\hline Hives & 1.5 & 1.3 & 1.4 \\
\hline Food allergy & 13.4 & 14.7 & 14.1 \\
\hline Headache & 25.8 & 24.6 & 25.2 \\
\hline \multicolumn{4}{|c|}{ Psychiatric diagnosis by a physician or psychologist } \\
\hline Any psychiatric diagnosis & 1.8 & 4.6 & 3.2 \\
\hline ADHD & 0.3 & 1.4 & 0.9 \\
\hline Autism & 0.3 & 1.0 & 0.6 \\
\hline Anxiety & 0.1 & 0.1 & 0.1 \\
\hline Tourette's syndrome & 0 & 0.2 & 0.1 \\
\hline Compulsion & 0.1 & 0.2 & 0.1 \\
\hline \multicolumn{4}{|l|}{ Physical activity } \\
\hline 4-5 times a week or more & 43.2 & 50.9 & 47.1 \\
\hline \multicolumn{4}{|l|}{ Life events } \\
\hline Life events (any) & 23.4 & 26.9 & 25.2 \\
\hline Car accident & 0.8 & 0.9 & 0.8 \\
\hline Other serious accident & 14.7 & 17.6 & 16.2 \\
\hline Witness to car accident & 1.8 & 2.1 & 1.9 \\
\hline Robbed & 1.6 & 2.3 & 1.9 \\
\hline Been hit more than once & 2.2 & 4.6 & 3.4 \\
\hline Witness to fire accident & 4.0 & 3.8 & 3.9 \\
\hline Witness to any violent crime & 1.3 & 0.8 & 1.1 \\
\hline
\end{tabular}


were reported to have been in, or witnessed, a major traumatic life event.

\section{Birth Characteristics of Twins in the STR}

It has been suggested that intrauterine exposure may influence subsequent risk of several psychiatric and chronic diseases (Barker, 1998). Although this hypothesis has been supported by previous research, these studies generally suffer from failure to adjust for possible confounds, such as genetic or early environmental factors, and they may also have limited power or low range of exposure. Twin studies present an ideal opportunity to disentangle associations between birth characteristics and diseases with regard to intrauterine environment, genetic factors, and environment early in life. We are now augmenting the registry with information on birth characteristics retrieved from birth records of all twin pairs born in Sweden from 1926 to 1958.

At birth, information about maternal and birth characteristics is routinely collected and documented in individual birth records by the attending midwife. These birth records are kept at local delivery archives throughout Sweden. This procedure of recording birth information and preserving the records is enforced by law. The birth records include information about maternal age at delivery, number of previous births, father's and/or mother's occupation (used to define socioeconomic status at birth), name (if baptized at birth), birthweight, birth length, head circumference, and gestational age (based on the last menstrual period). Correct birth identification of each twin within same-sex twin pairs has been ensured by only including same-sex twin pairs who were both baptized and named at birth, or who reported birth order with mutual within pair agreement in SALT. Information about birth order was validated in 2713 same-sex twin pairs who were both baptized at birth and responded to the question on birth order in SALT. There was a 95\% agreement between birth order as stated in SALT and as stated on birth records. We retrieved birth records in 22,097 twin pairs $(81 \%$ retrieval rate among the eligible twin pairs), and were able to identify birth characteristics of each twin in 12,166 same sex-twin pairs and 8533 opposite-sex twin pairs.

\section{Collaboration}

The STR is a resource for the international scientific community. We are therefore receptive to collaboration with academic and industry based researchers. Regardless of the type of research interest, all potential collaborations or data access agreements must first be reviewed by the Steering Committee of the STR. If the applicant is not based at a Swedish university, to assure that the Swedish research community benefits from this national resource, we require them to have a collaborator based at a Swedish university.

Today the STR collaborates scientifically with researchers all over the world. For our data sharing policy see http://www.meb.ki.se/twinreg/info/twinreg _ pol_stat.pdf, and for further inquiries and applications please contact the coordinator for the Swedish Twin Registry: tvillingregistret@meb.ki.se

\section{Acknowledgments}

Funding for the STR has been provided by multiple sources including the Swedish Department of Higher Education, the Swedish Scientific Council, AstraZeneca, NIH, the Swedish Heart and Lung Foundation, The Swedish Cancer Society, The Swedish Council For Working Life and Social Research, and the Swedish Research Council .

\section{References}

Barker, D. J. (1998). In utero programming of chronic disease. Clinical Science, 95, 115-128.

Bulik, C. M., Sullivan, P. F., Tozzi, F., Furberg, H., Lichtenstein, P., \& Pedersen, N. L. (2006). Prevalence, heritability and prospective risk factors for Anorexia nervosa. Archives of General Psychiatry, 63, 305-312.

Cameron, A. J., Lagergren, J., Henriksson, C., Nyren, O., Locke, G. R., III, \& Pedersen, N. L. (2002). Gastroesophageal reflux disease in monozygotic and dizygotic twins. Gastroenterology, 122, 55-59.

Crowe, M., Andel, R., Pedersen, N. L., Fratiglioni, L., \& Gatz, M. (2006). Personality and risk of cognitive impairment 25 years later. Psychology and Aging, 21, 573-580.

Evengard, B., Jacks, A., Pedersen, N. L., \& Sullivan, P. F. (2005). The epidemiology of chronic fatigue in the Swedish Twin Registry. Psychological Medicine, 35, 1317-1326.

Finkel, D., \& Pedersen, N. L. (2004). Processing speed and longitudinal trajectories of change for cognitive abilities: The Swedish Adoption/Twin Study of Aging. Aging, Neuropsychology, and Cognition, 11, 325-345.

Gatz, M., Fratiglioni, L., Johansson, B., Berg, S., Mortimer, J. A., Reynolds, C. A., Fiske, A., \& Pederson, N. L. (2005). Complete ascertainment of dementia in the Swedish Twin Registry: The HARMONY study. Neurobiology of Aging, 26, 439-447.

Gatz, M., Reynolds, C. A., Fratiglioni, L., Johansson, B., Mortimer, J. A., Berg, S., Fiske, A., \& Pederson, N. L. (2006). The role of genes and environments for explaining Alzheimer's disease. Archives of General Psychiatry, 63, 168-174.

Kato, K., Sullivan, P. F., Evengard, B., \& Pedersen, N. L. (2006a). Importance of genetic influences on chronic widespread pain. Arthritis and Rheumatism, 54, 1682-1686.

Kato, K., Sullivan, P. F., Evengard, B., \& Pedersen, N. L. (2006b). Premorbid predictors of Chronic Fatigue. Archives of General Psychiatry, 63, 1267-1272. 
Kendler, K. S., Gatz, M., Gardner, C. O., \& Pedersen, N. L. (2006). A Swedish national twin study of lifetime major depression. American Journal of Psychiatry, 163, 109-114.

Lichtenstein, P., De Faire, U., Floderus, B., Svartengren, M., Svedberg, P., \& Pedersen, N. L. (2002). The Swedish Twin Registry: A unique resource for clinical, epidemiological and genetic studies. Journal of Internal Medicine, 252, 184-205.

Lichtenstein, P., Tuvblad, C., Larsson, H., \& Carlström, E. (in press). The Swedish Twin study of CHild and Adolescent Development: The TCHAD-study. Twin Research and Human Genetics.

Mackintosh, M. A., Gatz, M., Wetherell, J. L., \& Pedersen, N. L. (2006). A twin study of lifetime Generalized Anxiety Disorder (GAD) in older adults: Genetic and environmental influences shared by neuroticism and GAD. Twin Research and Human Genetics, 9, 30-37.

Michaelsson, K., Melhus, H., Ferm, H., Ahlbom, A., \& Pedersen, N. L. (2005). Genetic liability to fractures in the elderly. Archives of Internal Medicine, 165, 1825-1830.

Mucci, L., Björkman, L., Douglass, C. W., \& Pedersen, N. L. (2005). Environmental and heritable factors in the etiology of oral diseases: A population-based study of Swedish twins. Journal of Dental Research, 84, 800-805.

Pedersen, N. L., Lichtenstein, P., \& Svedberg, P. (2002). The Swedish Twin Registry in the third millennium. Twin Research, 5, 427-432.

Peltonen, L. (2003). GenomEUtwin: A strategy to identify genetic influences on health and disease. Twin Research, 6, 354-360.

Rasgon, N. L., Magnusson, C., Johansson, A., Pedersen, N. L., Elman, S., \& Gatz, M. (2005). Endogenous and exogenous hormone exposure and risk of cognitive impairment in Swedish twins: A preliminary study. Psychoneuroendocrinology, 30, 558-567.

Soldani, F., Sullivan, P. F., \& Pedersen, N. L. (2005). Mania in the Swedish Twin Registry: Criterion validity and prevalence. Australian and New Zealand Journal of Psychiatry, 39, 235-243.

Svensson, D. A., Waldenlind, E., Ekbom, K., \& Pedersen, N. L. (2004). Heritability of migraine as a function of definition. Journal of Headache and Pain, 5, 171-176.

Wirdefeldt, K., Gatz, M., Schalling, M., \& Pedersen, N. L. (2004). No evidence for heritability of Parkinson disease in Swedish Twins. Neurology, 63, 305-311. 